\title{
Evaluation of the Process of Development of Higher Education Institutions in the Russian Federation
}

\author{
Elena Blagireva \\ Russian State Specialized Arts Academy \\ Moscow, Russia
}

\begin{abstract}
Innovative development of any organization from improving approaches to management of highly skilled professionals. To increase the efficiency of educational institutions, we need to search proactively for mechanisms of adjusting educational institutions to new realities that would allow education quality increase. This article provides an assessment of a competitive position of a higher education institution, and offers a model of proactive implementation of economic tools for a higher education institution management, with the purpose of optimization and efficiency increase.
\end{abstract}

Keywords-education; efficiency; accessibility; creation of special conditions; educational institution competitiveness; quality

\section{INTRODUCTION}

An educational system literally makes a personality, a lifestyle, plays a crucial role in the formation of a new generation of professionals [1]. As economy is getting more smart, a close connection of education with economy can be traced not only in the development of human capital, but in ensuring economic growth and the growth of human income, meeting the demands for highly skilled professionals on the labour market.

\section{TOOLS FOR MONITORING THE STATE OF DEVELOPMENT OF EDUCATIONAL INSTITUTIONS}

Monitoring, which means regular analysis, review, assessment of the state of the development of educational institutions on the market of educational services is a necessary, crucial element of control, which predefines the quality of the services provided by ensuring the possibility of efficiency increase of educational institutions, their potential to meet the strategic goals set for the development of the education sector in the Russian Federation.

A set of indicators plays a key role in the test of the process, opens up possibilities to correct the process based on the development of relevant measures in the educational policy.

Ministry of Education and Science of the Russian Federation has developed a set of procedures for regular monitoring of the development of educational institutions in order to increase their competitiveness, which is done based on the following indicators:
- Educational activity;

- Scientific research potential;

- International activity;

- Financial and economic activity;

- Compensation of academic teaching staff;

- Job placement;

- Infrastructure potential;

- A share of holders of Candidate of Sciences and Doctor of Philosophy degrees among academic teaching staff, and others.

Despite the ample nature of efficiency indicators, such monitoring does not fully account for the specific nature of activity of educational institutions (the way the specific nature of educational institution activity is accounted for when calculating such indicator values as scientific research, job placement, a share of holders of Candidate of Sciences and Doctor of Philosophy degrees among academic teaching staff, does not reflect individual particularities of one or another direction of educational institutions, special aspects of teaching students, as well as specifics of job placement of the graduates from one or the other industry).

Trends of education globalization raise a lot of questions for every higher education establishment, the central of which is how to gain a competitive edge, or an advantage, and keep it in the fast changing conditions of a competitive environment. A competitive advantage in this case means how you can get advantages on the market of educational services by consolidation of available resources and their more effective arrangement. It is believed that not more than a half of all the existing organizations that provide educational services to consumers have competitive advantage. Gaining a competitive advantage depends directly on solving the problem of effective institution management, an educational institution in this case.

Assessment of an institution potential is based primarily on business reputation, a "potential" (from Latin, potentio is power, i.e. means, resources, sources that can be used, mobilized to reach a certain goal), as a combination of a variety of resources required to perform a relevant kind of activity taking into account its specific nature. 
A competitive advantage is based on internal and external key competencies, which make it possible for an institution to become competitive and to remain so. This strategy means a control of standards, system compatibility of products and services, work of functional teams. Such competencies rest on experience, knowledge, effective management and do not lose their value when being used. On the other hand, such competencies need to be updated, without the constant use the experience is lost. The constantly changing conditions of a competitive environment sooner or later will make current key competencies outdated. That means that competitiveness depends on the creation of new competencies. But to create competencies for tomorrow, special qualities are required - dynamic abilities. Creating key competencies require an accumulation and integration of skills found both inside and outside an organization. Therefore, when creating key competencies, the ability to integrate different experience is as important as the ability to create new.

Dynamic abilities mean the ability to integrate experience to develop and reform external and internal competencies so that to keep with the fast changing environment. This way, the dynamic abilities reflect the ability of an institution to create new, advanced forms of key competencies in a certain context.

Examining the aspects of key competencies and dynamic abilities in order to earn a competitive advantage, one should note the importance of a system of corporate values, i.e. beliefs and organizational norms shared by all employees. These provisions of how to work out the strategies that make it possible for a company or an organization to gain a competitive advantage can be fully applied to the strategy of control over the development of educational institutions, the majority of which function in a competitive environment.

A potential of an educational institution can also be assessed by assessing a contribution of an educational institution - such approach suggests using an array of efficiency indicators.

In such a case the intensity of contribution of each educational institution, taking into account the specific nature of activity, can be characterized as:

- $\quad$ active contribution;

- $\quad$ passive contribution;

- neutral contribution.

The assessment of efficiency (competitiveness) of an educational institution suggests identifying its principal competitive advantages and its ability to participate in interregional and international rating-systems based on efficiency indicators.

Another indicator can be the introduction of innovative approaches that focus on innovative nature of an educational institution, as an important indicator of increasing the activity efficiency in modern conditions.

It should be noted that there is no single approach to assessment yet. However, the assessment of an innovative potential should ideally be rested on qualitative and quantitative examination of all its constituents, as well as the result of their impact on the process of forming an innovation potential in one sphere or sector or another. Thus, for example, if the presence of a talent pool of academic staff engaged in scientific research can be assessed by quantitative characteristics, then qualitative assessment should mean the ability of academic staff to generate new scientific knowledge, be involved in the scientific quest. It is evident that qualitative assessment of a scientific research potential is the most complicated because of the lack of tools and highly biased nature of an object under assessment.

In view of the above, primarily quantitative assessment methods are used now, and the latter is based on the use of statistics (Rosstat). Starting from 1993, the methodology and tooling used to analyze statistically the scientific potential has been reviewed in Russia taking into account international standards, the principal of which in the sphere of methodology for collecting the statistics on science and innovations is Frascati Manual. International statistics of science and innovations itself, based on coordinated efforts for standardization of innovation research programs, aims at improving international comparability of statistical data regarding the science and technology to improve the efficiency of the global scientific and technical progress.

Principal provisions of the methodology of statistical analysis of scientific and technical activity used in international statistical proceedings are being developed by the following international organizations:

- Organization for Economic Cooperation and Development - OECD, which activity is aimed at assisting member countries (developed countries) to develop measures to increase economic growth (development) rates; it was the very Group of National Experts on Science and Technology Indicators, acting as part of OECD, who developed the Frascati Manual in the Italian town of Frascati in 1963, and it became the first document setting forth the methodology for collecting statistics about research and development. Today, owing to multiple initiatives of OECD associated with elaboration of the Manual and the practice of its use, the last edition of this document (1993) has become a major international standard. Later on, taking into consideration the demand for the development of special standardized recommendations on the issues of statistical examination of topical aspects of the development of science and technology, their provision with resources, efficiency, impact on economic growth on a national and international scale, the experts of OECD prepared a series of methodological manuals that form the so-called "Frascati Family". Russia cooperates with OECD on the major activities, such as science policy, education, etc. OECD is mostly active in Russia in the following fields: fighting corrupt practices and bribery, economy, agriculture, education, labour market and social policy, the development of regions, promotion of competition, etc. 
- UNESCO, or United Nations Educational, Scientific and Cultural Organization, which exists from 1946 uniting over 175 countries with the purpose of promoting peace and international safety by fostering cooperation between countries related to awareness, science and culture. In 1978 UNESCO approved "Recommendation concerning the International Standardization of Statistics on Science and Technology", in furtherance of which UNESCO's "Manual for statistics on Scientific and Technological Activities" was published in 1984 (the document is being continuously revised taking into account the experience of the "Frascati Manual".)

The activity of OECD and UNESCO related to improving methodological foundations of statistical analysis and evaluation of scientific and technical activity and innovation potential is aimed not only at setting up common approaches to the study of modern aspects of global development of science and technology, but also at their promotion globally, this way ensuring the acceleration of rates and change in the direction of this development. The analysis of statistical data (according to the provisions of UNESCO's "Recommendation concerning the International Standardization of Statistics on Science and Technology" it should be updated every two years) should ensure comprehensive monitoring of a vector of scientific and technological progress.

In the author's opinion, educational institutions with the purpose of increasing the activity efficiency can use such methods of economic analysis, as:

- SWOT analysis (allows evaluating "strong" and "weak" sides of an organization, identify viable lines of development, opportunities and threats);

- building a competitive profile, which makes it possible to assess relative importance of increasing an effectiveness of individual factors of educational environment (current state and prospects of further development; business reputation; infrastructure; interaction of the market of educational services with the labour market);

- $\quad$ introduction of quality management system.

The environment in which an organization operates today is characterized by fast changes, globalization of markets and advent of new knowledge as a primary resource. Quality does not only affect the consumer satisfaction: it can also have direct impact on the institution reputation. Quality management system includes actions with the help of which an organization sets up its goals and defines processes and resources required to achieve such goals.

Quality management system controls cooperative processes and resources required to ensure value and implementation of results for the parties involved and allows higher management to optimize the use of resources, taking into account long- and short-term consequences of their decisions. [2].

\section{CONCLUSION}

It should be again emphasized that it is practically impossible for an educational institution to win in a competitive struggle and earn (take) its place on the market in modern conditions without accounting for the peculiarities of educational services, intensive use of economic instruments. It should be noted that we cannot get an extensive, complex and detailed specification of an educational institution activity without further improvement in assessment and monitoring of efficiency of higher education institutions activity.

\section{REFERENCES}

[1] A.O. Blinov, E. N. Blagireva, O. S. Rudakova. Interactive methods in an educational process. Work book. - M.: NAUCHNAYA BIBLIOTEKA Publishing House. 2014. - pp. 3-7.

[2] GOST R ISO 9000-2015. National Standard of the Russian Federation. Quality Management Systems. Fundamentals and vocabulary (approved by Order No.1390-st of Rosstandart dated September 28, 2015)

[3] http://xn--80abucjiibhv9a.xn--p1ai/ - Ministry of Education and Science of the Russian Federation

[4] http://oecdru.org - The Organization for Economic Co-Operation and Development (OECD). 